\title{
Assessment of parting rock weak zones under the joint and downward mining of coal seams
}

\author{
Volodymyr Bondarenko ${ }^{1}$, Iryna Kovalevska ${ }^{1,{ }^{*}, \text { Hennadii Symanovych }}{ }^{1}$, Mykhailo \\ Barabash $^{2}$ and Vasyl Snihur ${ }^{3}$ \\ ${ }^{1}$ National Mining University, Underground Mining Department, Dnipro, Ukraine \\ ${ }^{2}$ LLC "DTEK Energy", Department of Coal Production, Kyiv, Ukraine \\ ${ }^{3} \mathrm{MM}$ "Pershotravenske", PJSC "DTEK Pavlohradvuhillia”, Pavlohrad, Ukraine
}

\begin{abstract}
The aim of the forecasting effort is to identify troublesome zones of stability loss by a parting lengthwise of the extraction panel under the joint and downward mining of coal seams. Analyses have been carried out of active stress component curves for a 3-D model computational experiment compared with the strength characteristic of each lithotype of a parting. An algorithm has been developed for the stability assessment of a parting lengthwise along the extraction panel. The relationship patterns have been estimated between the sizes of the parting rocks discontinuity zones and the main geomechanical parameters. A scientifically grounded basis has been created for the detection of the parting rock weak zones lengthwise along the extraction panel for the calculation of the mounting and security systems of the development works. A complex of underground instrumental observations was made, which was used to set up a correspondence of patterns to indicate the variation in rock pressure manifestation intensity and the tendencies for changes in the parting structure. All of this confirms the adequacy of the techniques for parting state forecasting, which is recommended for use in the engineering documentation for the joint and downward mining of coal seams.
\end{abstract}

Keywords: coal seams, joint mining, computational experiment, stability

\section{Introduction}

For several years in the Western Donbas mines research and development work has been carried out in order to study the structural transformation of parting rock caused by the joint and downward mining of two or three coal seams in series. These transformations were researched from the viewpoint of rock pressure manifestations control, and at the same time as a way to implement the significant concentration and intensification of coal-face works with the benefit of obtaining the corresponding technical-and-economic parameters. So far, the main scientific and practical results achieved are as follows $[1-4]$ :

1. It was established that under the joint mining of coal seams (not classified as contiguous grade) abnormal areas of rock pressure are manifested $[1,2]$ at the coal-face

*Corresponding author: kovalevska_i@yahoo.com 
operation in a wide range of parting thicknesses up to $20-50 \mathrm{~m}$.

2. The parting rock structure systematization under the condition of joint and downward mining of coal seams in Western Donbas made it possible to allocate the five most common geological structures [3]. They have been provided as the basis for (using the finite element method) the calculation of abnormal areas of rock pressure manifestation, the subsequent assessment of the parting stability and corresponding decision-making as to the development, fastening, and maintenance of both mine workings and coal-face works.

3. A comprehensive methodology for carrying out multivariate computational experiments has been developed. It consisted of a three staged logical detection and account of the structural transformations of the parting rocks under the process of the joint and downward mining of coal seams. This provided an increasingly proficient degree of geomechanical process modelling in order to obtain more exact results for the parting rocks stress-strain state calculation by means of representation in the models of the most significant structural disturbances of each lithotype in the coal-bearing massif for the whole period of the mining operation: the preparation of extraction panels on the overlying seam, its mining with simultaneous development works on the underlying seam and subsequent coal-face works on it.

4. As a result of the stress-strain state calculations of the parting rocks, it has been established that the vertical stress concentrations penetrate the overlying seam bottom to the middle of the parting thickness and deeper, and constitute a danger of weakening the soft wet argillite and siltstone at a depth of $200-300 \mathrm{~m}$, a discontinuity occurs at a depth of $400 \mathrm{~m}$ in their naturally wet state. Below that depth, the vertical stress concentrations extend to the underlying seam and create rock pressure, which increases by $20-50 \%$ on the support construction of existing works [1]. This makes it possible to develop in advance the measures for the strengthening of development works to support construction in dangerous areas [4].

Accordingly, the aim of the article is the assessment of the parting rock weak zones under the joint and downward mining of coal seams. The studies have been carried out on the basis of a computational experiment by means of the finite elements method, the mining observations of rock pressure manifestations and their comparative analysis.

\section{Calculation of the weak zones of parting rocks}

The calculation principle of the weak zone is to compare each of the active stress components $\sigma_{y}, \sigma_{x}$ and $\sigma_{z}$ with a condition of absolute unloading (criteria $\sigma_{x}=0, \sigma_{z}=0$ and $\sigma_{y}=0$ ), when the process of parting rock segregation with tensile forces begins. But in areas where compressive stresses take precedence, the intensity of stresses $\sigma$ is equal to the calculated ultimate compressive strength value $R_{i}^{R, B}$ of one lithotype or another [3].

The calculation algorithm of discontinuity areas of the parting lithotypes presumes the isoline contours $\sigma_{y, x, z}=0$ for the determination under each of curves $\sigma_{y}, \sigma_{x}$ and $\sigma_{z}$ stress components; also the isolines $\sigma \geq R_{i}^{R, B}$ are plotted for each lithotype by the curve $\sigma$. For this purpose in each particular area of the model, at a specific value of $R_{i}^{R, B}$ an integrated application is used, this makes it possible to plot the contours of pointed isolines taking into account a certain defined accuracy. Then, the contours of all isolines $\left(\sigma_{y, x, z}=0\right.$ and $\left.\sigma=R_{i}^{R, B}\right)$ are united in a section of the model and a single overall external contour of the weak zone of the rock is plotted in general.

Some fragments of bottom rock discontinuity areas in the mining of an overlying seam $\mathrm{C}_{10}{ }^{t}$ are demonstrated by a depth increase $y_{B}$ of their distribution with an increase in depth $H$ of coal seam mining (Fig. 1). The relationship between depth $y_{B}$ of bottom rocks weakening during the mining of seam $\mathrm{C}_{10}{ }^{t}$ with strength characteristics $R_{i}^{R, B}$ may be observed for all the structures of a parting, but the tendency of $y_{B}$ to decrease due to increases in $R_{i}^{R, B}$ is based on the influence of thickness $m^{B}$ and depth $h^{B}$ of the stratification in the sandstone bottom, which 
adds to the pattern of significant ambiguity, which in turn does not allow for approximation by any function.

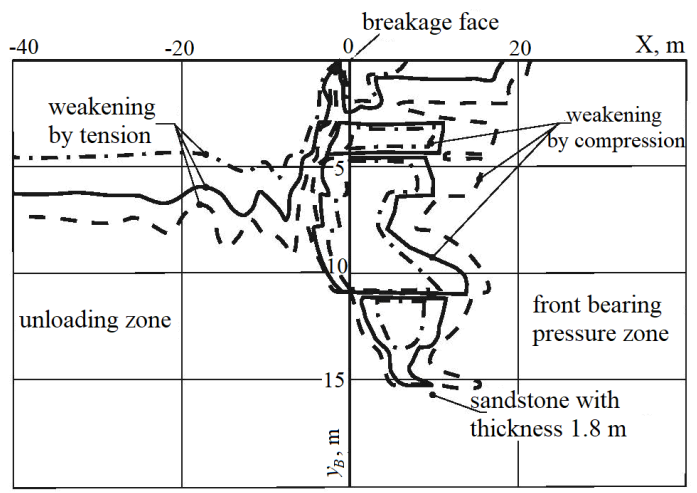

Fig. 1. The curves of the fragments of mining depth have influence $H$ on the discontinuity area sizes of the seam $C_{10}{ }^{t}$ bottom: ${ }^{-\cdot-} H=300 \mathrm{~m}$; $H=400 \mathrm{~m} ;---H=500 \mathrm{~m}$.

The similar tendencies of height $y_{R}$ of the roof rock weak zone relationship with geomechanics parameters $H$ (Fig. 2) and $R_{i}^{R, B}$ are observed in the roof of the seam $C_{8}{ }^{l}$; these patterns are also violated by the ambiguous influence of parameters $m_{i}^{R}$ and $h_{i}^{R}$ on sandstone stratification. Special attention is given here to the tendencies towards the influence of sandstone stratification parameters. Therefore, the sandstone in the main roof with average strength characteristics (in Western Donbas conditions) of lithotypes of a parting is capable of localising the upper part of the weak zone even at its average thickness, and detaching it from the main one, this characteristic is positively affected by the parting's stability. With the occurrence of thick sandstone $(3.0-5.0 \mathrm{~m})$, not only weak zone decomposition occurs into separate "foci", there is a decrease in the overall height of the disturbances extension by $2.2-2.3$ times.

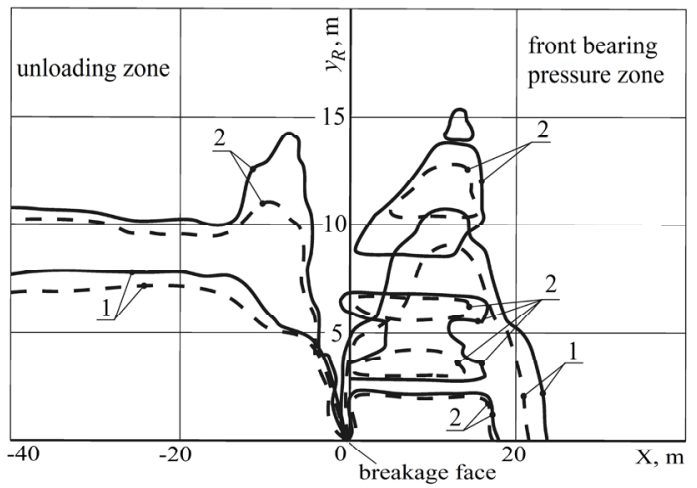

Fig. 2. The curves of fragments of mining depth $H$ and the parting structure type has an influence on the discontinuity area sizes of the roof rocks in the underlying seam: 1 - coarse-grained and mediumbedded structure; 2 - medium- and thin-bedded structure; - - $H=300 \mathrm{~m} ;-H=500 \mathrm{~m}$.

Thereafter, the volumes of weakened rocks are decreased even more intensively (by 3.5 times). In the unloading zone behind the longwall, the reduction in the height of the main roof rock segregation goes as far as 3 times with sandstone with a thickness of $5.0 \mathrm{~m}$.

Summing up the results of the studies, it is necessary to acknowledge (in terms of the roof rocks of underlying seam) in a formulated form before thesis (in terms of the overlying seam bottom) about the complexity and ambiguity of the geomechanical parameters that have an 
influence over weak zone sizes and the assessment of the degree of the parting rocks stability. Nevertheless, due to the wide variety of the parting rocks and stress-strain state calculations, the base for the development of specific and, at the same time, resumptive predictive assessments of the parting stability under the joint and downward mining of two or three coal seams, has been basically developed.

With regard to the most troublesome zones of parting rock stability probable loss, it is estimated that at approximate indifference of weak zones sizes in different segments of a parting along the length of the works, its stability should be assessed, at least, in three zones: in the front bearing pressure zone in advance of the longwall at a distance of $x \leq 7-9 \mathrm{~m}$; in unloading zone after the longwall withdrawal at a distance from the entrance of $z \leq 15-20$ $\mathrm{m}$ in direction of the mined-out space, and in the lateral bearing pressure zone of the virgin coal seam.

The next stage of the study was concerned with the criterion of substantiation, which compares the overall thickness $y_{B}+y_{R}$ of the weak zones in the overlying seam bottom $y_{B}$ and in the underlying seam roof $y_{R}$ with the thickness $H_{m}$ of a parting, which loses its stability at:

$$
y_{B}+y_{R} \geq H_{m} .
$$

In view of geometric and physical inhomogeneity of the parting structure, the weak zones often have an "intermittent" form with the formation of a range of local subareas. To resolve the situation with regard to the stability assessment of undisturbed space intervals between adjacent local weak zones, supplemental criteria have been developed, which take into consideration the distances between surfaces of weakness and rheological factor impact. Therefore, the strength characteristics of the roof and bottom rocks, as well as coal $\sigma_{c o m p r}^{R, B, C}$ are accepted according to [5-8] and through the data of the Geological Survey of mines; their analysis made it possible to substantiate the following averaged ranges of compressive resistance variation (in the specimen) by lithotypes: coal - 30 - 40 $\mathrm{MPa}$; argillite $-10-20$ $\mathrm{MPa}$; siltstone - $15-25 \mathrm{MPa}$; sandstone $-30-60 \mathrm{MPa}$. As a result, in view of problem structures (in terms of stability) of a parting [3] three variants may be distinguished for the computational values distribution of the strength characteristics of lithotypes:

- variant A - partially saturated rocks along the lower boundary of compressive resistance: coal $R^{\text {coal }}=20 \mathrm{MPa}$, argillite $R_{i}^{R, B}=5 \mathrm{MPa}$, siltstone $R_{i}^{R, B}=10 \mathrm{MPa}$, sandstone $R_{i}^{R, B}=20 \mathrm{MPa}$;

- variant $\mathrm{B}$ - saturated rocks along the upper boundary of compressive resistance: coal $R^{\text {coal }}=30 \mathrm{MPa}$, argillite $R_{i}^{R, B}=10 \mathrm{MPa}$, siltstone $R_{i}^{R, B}=15 \mathrm{MPa}$, sandstone $R_{i}^{R, B}=$ $45 \mathrm{MPa}$;

- variant $\mathrm{C}$ - unsaturated rocks along the upper boundary of compressive resistance: coal $R^{\text {coal }}=40 \mathrm{MPa}$, argillite $R_{i}^{R, B}=20 \mathrm{MPa}$, siltstone $R_{i}^{R, B}=25 \mathrm{MPa}$, sandstone $R_{i}^{R, B}=$ $60 \mathrm{MPa}$.

For the stability criterion of direct use (1) and in view of the extreme ambiguity and unreliability of the functional relationship of coordinates $y_{B}$ and $y_{R}$ with the main influential factors, families of graphs are plotted for the parameters $y_{B}$ and $y_{R}$ calculations (Fig. 3 and 4). These characteristic curves in conjunction with criterion (1) allow us to detect potential problems over lengthwise areas of the mineable panel. 
a)

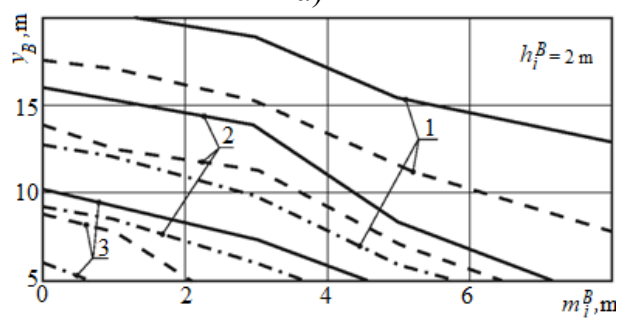

b)

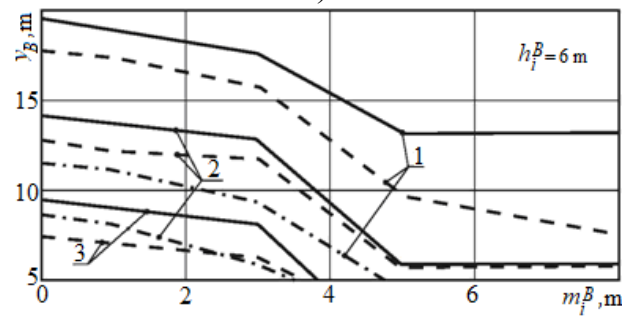

c)

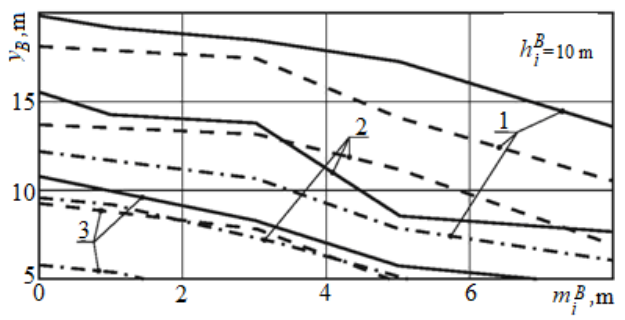

Fig. 3. The curves of the relationship between the depth $\mathrm{yB}$ of the bottom rocks weakening of the overlying seam with thickness $m_{i}^{B}$ and the depth $h_{i}^{B}$ of sandstone occurrence: a) $h_{i}^{B}=2 \mathrm{~m}$; b) $h_{i}^{B}=6 \mathrm{~m}$; c) $h_{i}^{B}=10$ m; 1 - variant A; 2 - variant B; 3 - variant $\mathrm{C} ;-\cdot-\cdot H=200 \mathrm{~m} ;---H=400 \mathrm{~m} ;-H=600 \mathrm{~m}$.

a)

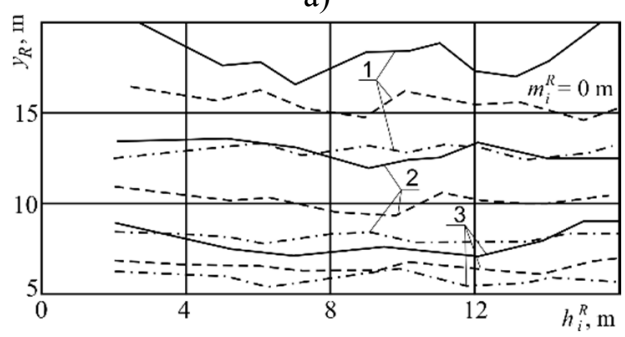

b)

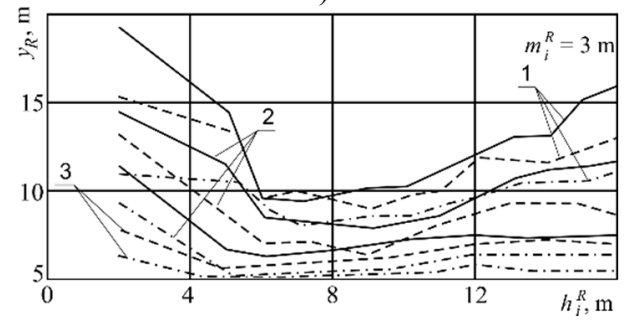

c)

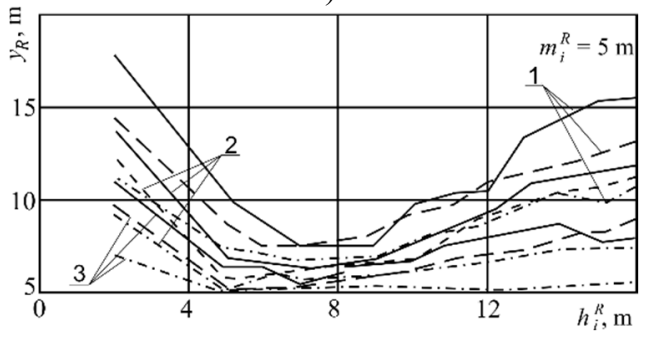

Fig. 4. The curves of the relationship between the height $y_{R}$ of roof rocks weakening of the underlying seam with height $h_{i}^{R}$ and thickness $m_{i}^{R}$ of sandstone occurrence: a) $m_{i}^{R}=0 \mathrm{~m}$; b) $m_{i}^{R}=3 \mathrm{~m}$; c) $m_{i}^{R}=5 \mathrm{~m}$; 1 - variant A; 2 - variant $\mathrm{B} ; 3$ - variant $\mathrm{C} ;-\cdot-\cdot H=200 \mathrm{~m} ;---H=400 \mathrm{~m} ;-H=600 \mathrm{~m}$.

The patterns described above make it possible to outline the areas of mining-andgeological conditions to definitively determine the stable state of a parting:

- due to the factor of the overlying seam roof rock weakening - the depth of sandstone occurrence is about $6 \mathrm{~m}$ where its thickness is not less than $3.0 \mathrm{~m}$;

- due to the factor of the underlying seam roof rock weakening - the height of sandstone occurrence is in the interval of $6-9 \mathrm{~m}$ where its thickness is not less than $3.0 \mathrm{~m}$. 
Thus, these ratios of rock weakening distribution vary according to the thickness of the parting and are determined not only by the mining depth and strength characteristics of lithotypes, but also by the sandstone thickness and height (depth) of its occurrence relative to mineable seams; the parting is stable (even in conditions of saturated rocks) with a sandstone thickness of more than $3 \mathrm{~m}$ and its location in the roof (bottom) of the seams at a distance of $6-9 \mathrm{~m}$. This provides a way to establish the range of mining-and-geological conditions, where downward and joint mining may be performed without considering the risk of stability loss by a parting.

\section{Forecasting the effect of troublesome zones on parting weakening}

Using graphs in Fig. 3 and 4 in combination with criterion (1), it is possible to make an assessment of parting stability. It is, however, connected with a number of calculations, extrapolations, and specifications of the sandstone sheet (sheets) location relative to the overlying and underlying seams. This complicates, in some ways, the algorithm for the stability assessment of a parting, especially with respect to the way in which this assessment is performed lengthwise along the mineable panel. Therefore, for the operational assessment of parting stability, a numerical analyses of curves has been performed (Fig. 3 and 4) in conjunction with criterion (1). This results in the determination of interface areas of the stable and unstable state of the parting rocks, which are shown in Fig. 5.

a)

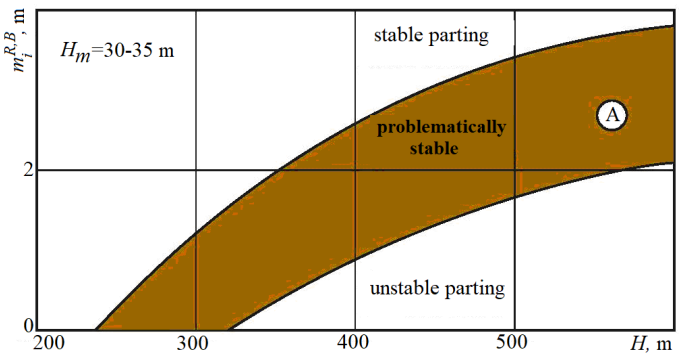

b)

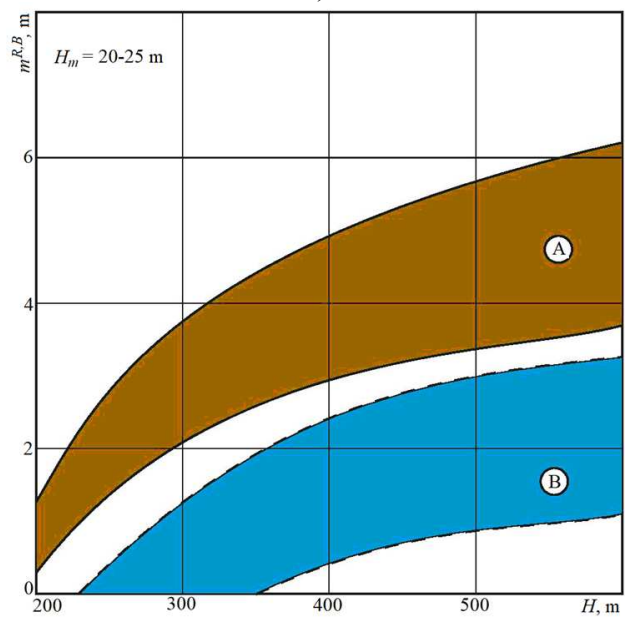

Fig. 5. Predictive areas of rock state of a parting with thickness: a) $H_{m}=30-35 \mathrm{~m}$; b) $H_{m}=20-25 \mathrm{~m}$; A - saturated rocks along the lower boundary of hardness; B - the rocks of average compressive resistance (as applicable to Western Donbas conditions). 
These interface areas make it possible to predetermine, at a preliminary stage, three variants in the mining-engineering situation: a parting is stable, a parting is unstable and problematically stable (it is possible that its stability loss may occur due to certain more specific geomechanical parameter ratios).

\section{The algorithm of the parting stability assessment}

The assessment of the parting stability lengthwise along the extraction panel is made in the following sequence:

1. The preliminary separation of a mineable panel length into areas of a stable parting and areas with a possible loss of stability are performed. This is done at the scientific assessment level, and the emphasis is on the areas with thin- and medium-bedded structure, saturated rocks (according to prediction), increased mining depth and decreased thickness of a parting.

2. Based on the mining-and-geological forecasting data and with the use of normative technique regulations [9] the strength characteristics of the parting rocks belong to one of three categories: A, B or C.

3. The structure of a parting in a specific area from a range of selected ones is studied, with the determination of sandstone thickness in the $m_{i}^{R, B}$ variation range, the depth $h_{i}^{B}$ of its occurrence in the overlying seam bottom and height $h_{i}^{R}$ of its distribution in the underlying seam roof. If there are two sheets of sandstone in the structure of a parting, the parameters $h_{i}{ }^{B}$ and $h_{i}{ }^{B}$ are determined for the upper sheet, but parameters $m_{i}^{R}$ and $h_{i}^{R}$ are specified for the lower sheet of sandstone.

4. With the use of Figure 5 a general assessment of the parting stability is made:

- in the category of "Stable parting", the studied area is excluded from further consideration, and mining in the underlying seam is performed without consideration of the influence of coal-face operation in the overlying seam;

- in the category of "Unstable parting", the mining and engineering measures are developed in the area to consider the influence of the coal-face operation in the overlying seam, such as, to improve the mounting and security systems in the underlying seam;

- in the category of "Problematically stable", it is necessary to study in greater detail the depth $y_{B}$ and height $y_{R}$ of disturbance extensions with the use of curves in Figures 3 and 4. Thereafter, the values $y_{B}$ and $y_{R}$ are calculated according to the curves in Figures 3 and 4 (with the use, if necessary, of an extrapolation between two adjacent single lines) and inserted into criterion (1):

- if the criterion is met, the studied area lengthwise along the mineable panel falls into the category of "Unstable parting" with the corresponding mining and engineering measures developed to improve the safety and reliability of mining operations in the underlying seam;

- in cases where criterion (1) is not met, this area falls into the category "Stable parting", and there is no need for any change of parameters for technological operations.

5. The stated algorithm of the parting stability assessment is performed throughout the length of the mineable panel with the addition of the necessary structural-and-technological measures to the engineering documentation of mining operations.

\section{Analysis of the underground investigation results}

To confirm the adequacy and reliability of the parting stability forecasting, a methodology for carrying out comprehensive underground instrumental observations has been developed. Two types of experimental characteristic curves have been obtained, which characterize the rock pressure manifestations in mining, for example, of the seam $C_{9}$ : directly in the breakage face by a relative ratio $\Delta$ of the extension variation of mechanized support for hydraulic props 
and in 914 development works by maximal $\left(u_{v}\right)_{\max }$ and average $\left(u_{v}\right)_{\text {aver }}$ which encounter the velocity of roof and bottom rocks in the area of intersection with 914 longwall faces (Zakhidno-Donbaska Mine, Western Donbas) [7].

An analysis of the characteristic curves (Fig. 6) confirmed a correspondence of patterns for indicator variation in rock pressure manifestation intensity and tendencies of changes in the parting structure lengthwise along the 914 mineable panels of the seam $C_{9}$ longwall face. In such a way, the underground investigation results made it possible to recommend the technique of parting stability forecasting for use in engineering documentation for the joint and downward mining of coal seams. For example, recommendations were developed concerning the choice of parameters for mounting and security schemes of the works in case of its reuse. These recommendations are based on the performed analyses of mining-andgeological conditions for the maintenance of the works, as well as on the computational experiment results of the geomechanical system stress-strain state calculations (Fig. 7).

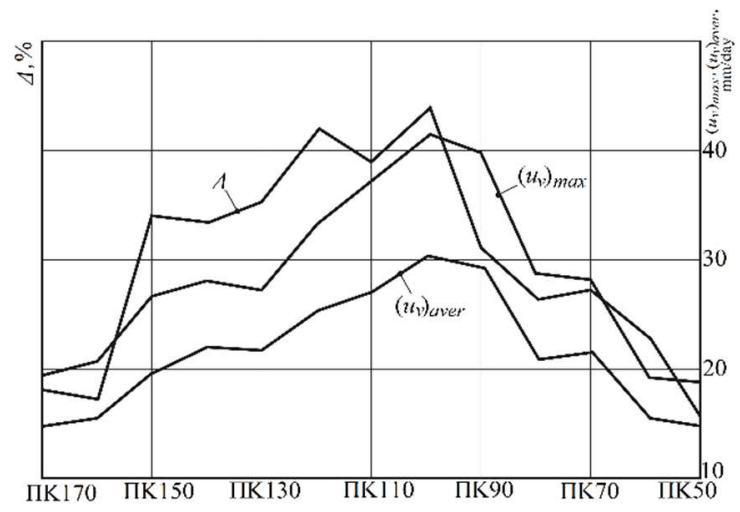

Fig. 6. Characteristic curves of $\Delta,\left(u_{v}\right)_{\max },\left(u_{v}\right)_{\text {aver }}$ indicators variation on the working unit with thinbedded structure of parting and saturated rocks in mining of the $C_{9}$ seam.

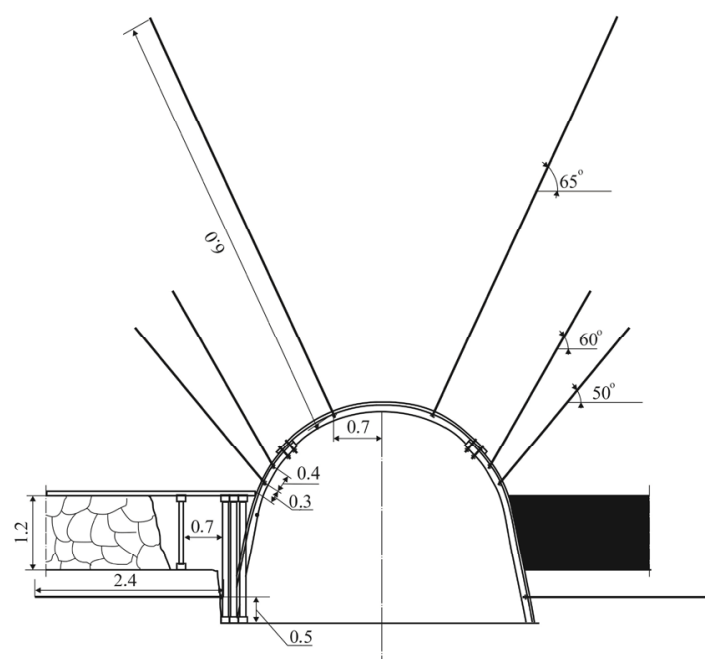

Fig. 7. The model of the recommended scheme for the maintenance of the works. 


\section{Conclusions}

1. It has been established, that in the front pressure zone of the longwall end areas, $7-9 \mathrm{~m}$ to the maintained works and behind the longwall at a distance up to $27-31 \mathrm{~m}$ from the mine works, the superposition of rock pressure manifestations occurs, this is caused by face works and the maintained works by itself. This provides grounds for the allocation of the longwall end area with a width of up to $20 \mathrm{~m}$ (from the drift towards the mined-out space) as one of the most troublesome areas from the viewpoint of the parting stability loss. Therefore, the unloading and bottom rocks segregation area deepens by $1.5-4.5$ times more than throughout the rest of the mined-out space. The account of this phenomenon allows for the making of a provision in the extraction panel mining passport for measures directed toward the adjacent massif strengthening in order to provide stability to the junction between the longwall and the works, when mining the troublesome zones.

2. The criteria and algorithms for the comprehensive assessment of parting rock stability have been substantiated.

A comprehensive assessment is provided by the account of segregation under the impact of tensile stresses $\sigma_{y, x, z} \geq 0$ in all three directions (Y,X, Z) of each parting lithotype occurring in space; the compression failure areas $\sigma \geq R_{i}^{R, B}$ also have a spatial representation and take into consideration the impact of factors, which weaken the rock, such as fracturing, water saturation and rheology. This allows for the determination of the patterns of discontinuity area development and their location in space of a parting taking into account its variable structure and strength characteristics, fracturing intensity and water saturation and liability to the creep deformation of lithotypes, which form a parting.

3. The main influential geomechanical parameters have been systemized and the patterns have been determined for their relationship with the depth of weakening in the overlying seam bottom and with the height of structural disturbances in the underlying seam roof. Patterns have been obtained in the form of graph families of the relationship between the sizes of parting rock discontinuity areas and the main influential factors: depth of mining $H$, parting thickness $H_{m}$ and compressive resistance $R_{i}^{R, B}$ of its lithotypes, thickness $m_{i}^{R, B}$ and vertical coordinate $h_{i}^{R, B}$ of sandstone distribution within the bounds of a parting.

4. A forecasting technique for the troublesome zones in a parting lengthwise along the mineable panel has been developed, which is distinguished by operational calculations and availability for use. This technique presents the possibility to detect in advance the problem areas for performing warning measures of safe and highly-productive mining in underlying seams.

The authors express their gratitude to senior management of "Pavlohradvuhillia DTEK" PLC and Mine Administration for the assistance in research development.

\section{References}

1. M.V. Barabash, State analysis of overworked and underworked parting between contiguous seams and during their simultaneous top-down mining. Min. Miner. Depos. 10, 2, 34-39 (2016) doi.org/10.15407/mining10.02.034

2. V.I. Bondarenko, I.A. Kovalevskaya, G.A. Simanovich, M.V. Barabash, V.G. Snigur, Vliyanie gorizontal'nykh napryazheniy na strukturnye preobrazovaniya porod mezhduplast'ya sovmestno otrabatyvaemykh ugol'nykh plastov $c_{10}^{v} i c_{9}$. Ugol' Ukrainy 4 , 35-39 (2017)

3. I. Kovalevska, M. Barabash, V. Snihur, Development of a research methodology and analysis of the stress state of a parting under the joint and downward mining of coal seams. Min. Miner. Depos. 12, 1, 76-84 (2018) doi.org/10.15407/mining12.01.076 
4. I.A. Kovalevskaya, G.A. Simanovich, M.V. Barabash, Ekspertnaya otsenka vybora krepezhnoy i okhrannoy sistem povtorno ispol'zuemykh vyrabotok pri otrabotke plasta $c_{8}^{n}$, Ugol' Ukrainy 12, 17-20 (2015)

5. B.M. Usachenko, V.P. Cherednichenko, I.E. Golovchansky, Geomekhanika okhrany vyrabotok v slabometamorfizirovannykh porodakh (Kyiv, Ukraine, 1990)

6. B.M. Usachenko, Svoystva porod i ustoychivost' gornykh vyrabotok. Kyiv: Naukova dumka (1979)

7. V.I. Bondarenko, I.A. Kovalevskaya, G.A. Simanovich, A.V. Martovitskiy, A.F. Kopylov, Metody rascheta peremeshcheniy i uprochneniya prikonturnykh porod gornykh vyrabotok shakht Zapadnogo Donbassa (Dnipropetrovsk, Ukraine, 2010)

8. I. Kovalevs'ka, G. Symanovych, V. Fomychov, Research of stress-strain state of cracked coal-containing massif near-the-working area using finite elements technique. Min. Miner. Depos., 159-163 (2013) http://www.scopus.com/inward/record.url?eid=2-s2.084892146430\&partnerID=MN8TOARS

9. SOU 10.1.001.85790.011:2007, Pidhotovchi vyrobky na polohykh plastakh. Vybir kriplennia, sposobiv i zasobiv okhorony (Donetsk, Ukraine, 2008) 